\title{
Study of Association Between Different Coronary Artery Disease Presentations and Its Effect on Short-Term Mortality, Readmission, and Cost in Patients Undergoing Percutaneous Coronary Interventions
}

\author{
Mansoor Ahmad ${ }^{1}$, Muhammad Asghar ${ }^{2}$, Udit Joshi ${ }^{1}$, Nathan A. Neilson ${ }^{3}$, Michael Tye ${ }^{3}$, Chirag Divecha \\ ${ }^{1}$, Minchul Kim ${ }^{4}$, Sudhir Mungee ${ }^{5}$ \\ 1. Cardiology, University of Illinois College of Medicine at Peoria, Peoria, USA 2. Internal Medicine, University of \\ Illinois Chicago, College of Medicine at Peoria, Peoria, USA 3. Cardiology, University of Illinois Chicago, College of \\ Medicine at Peoria, Peoria, USA 4. Internal Medicine, University of Illinois College of Medicine at Peoria, Peoria, USA \\ 5. Cardiology, University of Illinois College of Medicine, Order of St. Francis Medical Centre, Peoria, USA
}

Corresponding author: Mansoor Ahmad, mahmad1@uic.edu

\section{Abstract \\ Introduction}

Atherosclerotic coronary artery disease (CAD) is the major cause of mortality in the USA. CAD requiring percutaneous coronary intervention (PCI) can have a wide spectrum of presentations. We reviewed the cost of admission and PCI at the tertiary care center stratified for different CAD presentation types.

\section{Methods}

We performed a retrospective study of 7,389 patients undergoing coronary angiogram at our facility from 2015 to 2017. Patients were selected from CathPCI registry. Chart review was done for readmission and death data. Cost data were provided by the finance department. Patients going for coronary artery bypass surgery (CABG) were excluded. We split the patients based on their need for PCI. Cost analysis was based on CAD presentation types (No symptoms, atypical symptoms, stable angina, unstable angina, NSTEMI [non-ST segment elevation myocardial infarction], STEMI [ST-segment elevation myocardial infarction]). Adjusted linear regression was run for the outcomes. Primary outcomes were 30-day readmission and death. The secondary outcome was cost of admission.

\section{Results}

The final sample size was 6,403. The mean age was 65.6 years (SD: 12.5 ; male: 63.8\%). 2444 required PCI $(38 \% ; \mathrm{p}<0.001)$. PCI group had lower mean age (62.5 years; SD: 12.3 , $\mathrm{p}<0.001)$ with lower BMI (30.6 vs 31.1, $\mathrm{p}=0.015$ ). PCI group had significantly lower odds for 30-day readmission (OR: 0.63; CI: $0.45-0.89 ; \mathrm{p}=0.009$ )

Review began 06/03/2021 Review ended 07/21/2021 Published 08/03/2021

\section{() Copyright 2021}

Ahmad et al. This is an open access article distributed under the terms of the Creative Commons Attribution License CC-BY 4.0., which permits unrestricted use, distribution, and reproduction in any medium, provided the original author and source are credited. and 30-day mortality (OR:0.60; CI: 0.41-0.89; $\mathrm{p}=0.011$ ). A severe presentation increased the odds of getting PCI. Cost of admission was higher in all groups receiving PCI.

\section{Conclusions}

PCI group had better 30-day readmission and mortality rates. PCI increases the cost of admission in all CAD types.

\section{Categories: Cardiology}

Keywords: cost effectiveness analysis, primary percutaneous coronary intervention (pci), coronary artery disease, symptoms, symptoms severity scale

\section{Introduction}

Atherosclerotic coronary artery disease (CAD) is major cause of death in United States [1]. Percutaneous coronary artery intervention (PCI) remains the most common treatment modality among the treatments of coronary artery disease. More than 600,000 PCIs are performed in the United States each year, the cost associated with these procedures is estimated at around \$12 billion [2]. Although the mortality associated with the procedure is low, the readmission rate after the procedure is indicative of the quality of care and determines the cost of care [3]. The main determinants of cost-effectiveness are age and class of angina. PCI is most successful in the case of left ventricular disease and in younger patients [4].

For patients with stable angina COURAGE trial compared medical therapy with PCI and found the cost to be higher for the intervention arm [5]. However, a subsequent analysis done for stable angina patients has 
emphasized that the acceptable cost threshold for improvement in symptoms is difficult to achieve [6]. In patients with unstable angina and non-ST elevation myocardial infarction (NSTEMI) studies comparing the cost-effectiveness of early intervention versus conservative management revealed increased cost associated with the intervention [7]. In STEMI patients the cost-effectiveness of the PCI is reported in terms of length of stay (LOS), 30-day readmission, and mortality associated with the procedures, and these outcomes depend on the location of the lesion. Studies have shown that early discharge (3 days) after PCI is associated with decreased 30-day readmission rate and cost, especially in non-anterior wall myocardial infarction [8].

Based on varying outcomes in different CAD presentation types, it is difficult to calibrate the factors affecting the cost of admission. In this study, we looked at the admission cost associated with different types of coronary artery disease presentations with and without PCI.

The abstract from this article has been published in the National Meeting of Cardiology. SCAI 2019. https://onlinelibrary.wiley.com/doi/10.1002/ccd.28864.

\section{Materials And Methods \\ Patient population and study design}

We performed a retrospective analysis of 7,389 patients who had undergone coronary angiogram at our facility, between January 2015 and December 2017. Institutional Review Board approval was obtained from the office of Human Research at the University of Illinois Chicago at Peoria, IL. Initial patient number was 7,389. We excluded patients with incomplete records, those with missing labs and patients who required CABG. The final sample size was 6,403 . We used retrospective data from chart review, and every patient had an electrocardiogram (ECG) available before the procedure. Clinical variables evaluated are listed in Table-1. We split the patients in two categories based on whether the patient received PCI or not. Additionally, we divided patients based on their CAD presentation type at the time of the coronary angiogram. The CAD presentation classes included No symptoms, Atypical symptoms, Stable angina, Unstable angina, NSTEMI, and STEMI.

\section{Outcomes}

Primary outcomes were 30-day readmission and mortality. The secondary outcome was cost of admission.

\section{Statistical analysis}

Continuous data were reported as mean \pm standard deviation (SD) and categorical data as proportions. T-test was utilized to compare continuous variables and the Chi-square test was used for categorical variables. Adjusted statistical analyses were conducted to compare clinical variables. 30-day readmission, 30-day mortality, and admission cost required a multivariate analysis. We used Stata software, v12 for statistical analysis and p-value of less than 0.05 was marked as significant.

\section{Results}

\section{Sample demographics}

Of the total 6,403 patients, 2444 (38\%) patients received PCI compared with 3959 (62\%) who did not receive PCI (No-PCI group) (Table 1). Patients in the PCI group were comparatively younger (mean age of $64.5 \mathrm{vs.}$ $66 ; \mathrm{p}<0.001$ ) and had lower BMI (30.6 vs. $31.1 ; \mathrm{p}=0.015)$. There was a significantly higher proportion of male patients in the PCI group, compared with the No-PCI group $(70.9 \%$ vs. $59 \%$; $<<0.01)$. 


\begin{tabular}{|c|c|c|c|c|}
\hline Continuous variables & All $(n=6403)$ & $\mathrm{PCI}(\mathrm{n}=2444)$ & No PCI ( $n=3959)$ & p-value \\
\hline Age & 65.5 (12.5) & 64.5 (12.3) & 66.0 (12.5) & $<0.001$ \\
\hline BMI & $30.9(7.0)$ & $30.6(6.4)$ & $31.1(7.4)$ & 0.015 \\
\hline Categorical variables & All $(n=6403)$ & $\mathrm{PCl}(\mathrm{n}=2444)$ & No PCI (n = 3959) & $\mathrm{p}$-value \\
\hline Male & $4083(63.8)$ & $1732(70.9)$ & 2351 (59.4) & $<0.001$ \\
\hline Smoker & $1710(26.7)$ & 796 (32.6) & $914(23.1)$ & $<0.001$ \\
\hline Hypertension & $4932(77.0)$ & $1832(74.9)$ & $3100(78.3)$ & 0.002 \\
\hline Family history of CAD & 657 (10.3) & $288(11.8)$ & 369 (9.3) & 0.002 \\
\hline Prior MI & $1274(19.9)$ & $551(22.5)$ & 723 (18.3) & $<0.001$ \\
\hline Prior $\mathrm{HF}$ & $1193(18.6)$ & $253(10.3)$ & $940(23.7)$ & $<0.001$ \\
\hline Valve surgery & 127 (1.9) & $41(1.7)$ & $86(2.2)$ & 0.168 \\
\hline Prior PCI & $1492(23.3)$ & 703 (28.7) & 789 (19.9) & $<0.001$ \\
\hline Prior CABG & $641(10.0)$ & 200 (8.2) & $441(11.1)$ & $<0.001$ \\
\hline Current dialysis & $186(2.9)$ & $53(2.2)$ & $133(3.4)$ & 0.006 \\
\hline Prior CVD & 926 (14.5) & 334 (13.7) & $592(14.9)$ & 0.155 \\
\hline Prior PAD & $840(13.1)$ & $301(12.3)$ & $539(13.6)$ & 0.135 \\
\hline Chronic lung disease & $1158(18.1)$ & 389 (15.9) & 769 (19.4) & $<0.001$ \\
\hline Diabetes & 2165 (33.8) & 785 (32.1) & $1380(34.8)$ & 0.024 \\
\hline Prior cardio shock & $99(1.5)$ & $65(2.7)$ & $34(0.8)$ & $<0.001$ \\
\hline Prior cardiac arrest & $192(3.0)$ & $111(4.5)$ & $81(2.0)$ & $<0.001$ \\
\hline CAD presentation & & & & $<0.001$ \\
\hline 1: No symptoms & 740 (11.6) & $44(1.8)$ & 696 (17.6) & \\
\hline 2: Atypical Symptoms & $725(11.3)$ & $41(1.7)$ & $684(17.3)$ & \\
\hline 3: Stable angina & 1377 (21.5) & 317 (12.9) & $1060(26.8)$ & \\
\hline 4: Unstable angina & $1285(20.1)$ & $538(22.0)$ & 747 (18.9) & \\
\hline 5: Non-STEMI & $1410(22.0)$ & 775 (31.7) & $635(16.0)$ & \\
\hline 6: STEMI & $866(13.5)$ & $729(29.8)$ & $137(3.5)$ & \\
\hline
\end{tabular}

\section{TABLE 1: Sample demographics.}

Chi-square test for categorical variables and t-test for continuous variables.

\# of patients (portion \% by column)

CAD: coronary artery disease; MI: myocardial Infarction; HF: heart failure; PCI: percutaneous coronary intervention; CABG: coronary artery bypass graft; CVD: cardiovascular disease; PAD: peripheral arterial disease; CCS: Canadian Cardiovascular Society; Non-STEMI: non-ST elevation myocardial infarction.

\section{Clinical variables and $\mathrm{PCl}$ treatment}

Patients in the PCI group demonstrated a larger proportion of smokers $(32.6 \%$ vs $23.1 \%$; $<<0.001)$ and those with history of CAD (11.8\% vs 9.3\%; $\mathrm{p}=0.002$ ) (Table 1$)$. A significantly larger number of patients in the PCI group reported a history of previous MI $(22.5 \%$ vs $18.3 \%$; $p<0.001)$, prior PCI $(28.7 \%$ vs $19.9 \%$; $<<0.001)$ and prior cardiogenic shock ( $2.7 \%$ vs $0.8 \%$; $<0.001)$. Interestingly, significant number of patients in the No-PCI group had history of hypertension ( $78.3 \%$ vs $74.9 \%$; $=0.002$ ), chronic lung disease $(19.4 \%$ vs $15.9 \%$; $\mathrm{p}<0.001)$, diabetes $(34.8 \%$ vs $32.1 \%$; $\mathrm{p}=0.024)$, and heart failure $(23.7 \%$ vs $10.3 \% ; \mathrm{p}<0.001)$. Furthermore, 


\section{Cureus}

patients in the No-PCI group reported a history of prior CABG at a greater rate $(11.1 \% \mathrm{vs} 8.2 \%$; $\mathrm{p}<0.001)$ and were on dialysis more frequently $(3.4 \%$ vs $2.2 \%$; $\mathrm{p}=0.006)$. The No-PCI group had higher number of patients who presented with no symptoms (17.6\% vs $1.8 \%$ ), atypical symptoms (17.3\% vs $1.7 \%)$, and stable angina (26.8\% vs $12.9 \%$ ) (Figure 1 ). The PCI group had a significantly higher number of patients with NSTEMI (31.7\% vs $16 \%)$, and STEMI (29.8\% vs $3.5 \%$ ) compared with the No-PCI group.

$\square \mathrm{No} \mathrm{PCl} \quad \mathrm{PCl}$

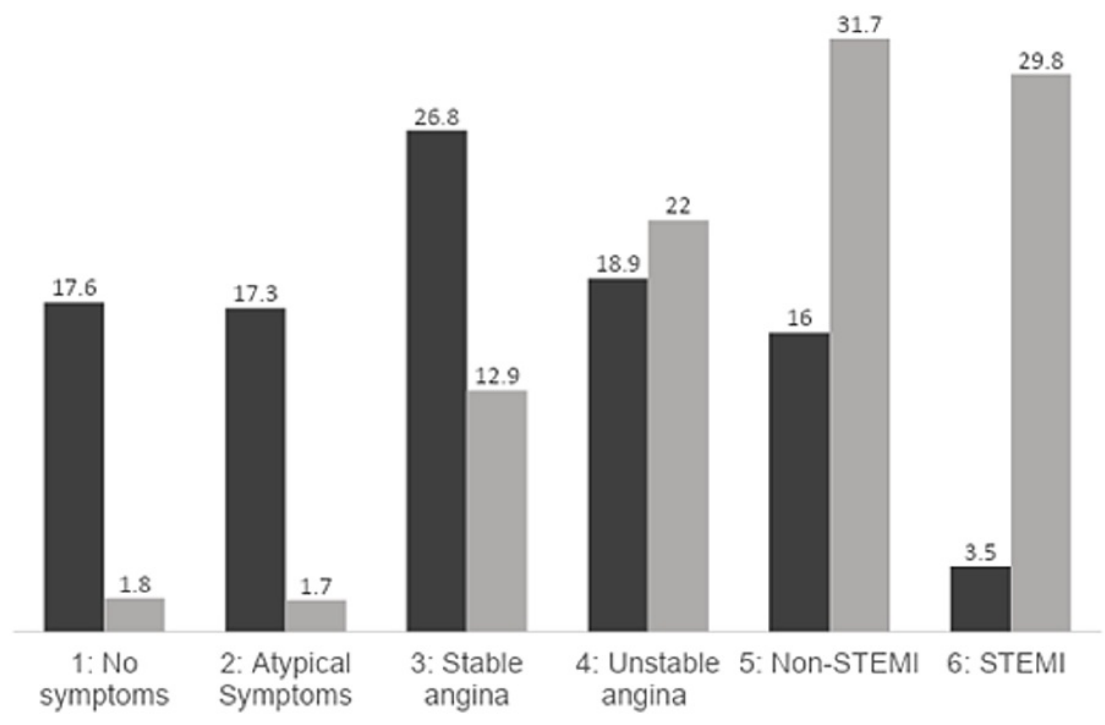

FIGURE 1: Percutaneous coronary intervention comparison in different coronary artery disease presentation types.

Percentage bar graph comparing $\mathrm{PCl}$ vs No-PCl ground among CAD presentation classifications.

\section{Predictors of $\mathrm{PCl}$ treatment}

On linear regression analysis (Table 2), male patients had higher odds of receiving PCI compared with female patients (OR: 1.82, CI: 1.6-2.08, p < 0.001). Patients with prior PCI (OR: 1.8, CI: 1.52-2.12, p < 0.001) and prior cardiogenic shock (OR: 1.82, CI: 1.03-3.22, $\mathrm{p}=0.040$ ) also had increased odds of receiving PCI. Patients with heart failure (OR: 0.62, CI: 0.52-0.75, p < 0.001), prior CABG (OR: 0.66, CI: 0.53-0.82, p < 0.001 ), and chronic lung disease (OR: $0.8, \mathrm{CI}: 0.68-0.94, \mathrm{p}=0.008$ ) demonstrated decreased odds of receiving PCI. 


\section{Cureus}

\begin{tabular}{|c|c|c|c|c|}
\hline Covariates & Odds ratio & p-value & \multicolumn{2}{|c|}{$95 \% \mathrm{Cl}$} \\
\hline Age & 1.00 & 0.104 & 1.00 & 1.01 \\
\hline BMI & 1.00 & 0.779 & 0.99 & 1.01 \\
\hline Male & 1.82 & $<0.001$ & 1.60 & 2.08 \\
\hline Smoker & 1.11 & 0.194 & 0.95 & 1.29 \\
\hline Hypertension & 1.04 & 0.630 & 0.89 & 1.22 \\
\hline Family history of CAD & 1.16 & 0.135 & 0.95 & 1.41 \\
\hline Prior MI & 0.94 & 0.483 & 0.78 & 1.12 \\
\hline Prior HF & 0.62 & $<0.001$ & 0.52 & 0.75 \\
\hline Valve surgery & 0.94 & 0.784 & 0.59 & 1.50 \\
\hline Prior PCl & 1.80 & $<0.001$ & 1.52 & 2.12 \\
\hline Prior CABG & 0.66 & $<0.001$ & 0.53 & 0.82 \\
\hline Current dialysis & 0.74 & 0.141 & 0.50 & 1.10 \\
\hline Prior CVD & 1.09 & 0.335 & 0.91 & 1.31 \\
\hline Prior PAD & 1.04 & 0.722 & 0.86 & 1.25 \\
\hline Chronic lung disease & 0.80 & 0.008 & 0.68 & 0.94 \\
\hline Diabetes & 1.00 & 0.946 & 0.87 & 1.14 \\
\hline Prior cardiogenic shock & 1.82 & 0.040 & 1.03 & 3.22 \\
\hline Prior cardiac arrest & 1.14 & 0.545 & 0.75 & 1.74 \\
\hline \multicolumn{5}{|c|}{ CAD presentation (Ref: no symptoms) } \\
\hline 2: Atypical symptoms & 0.74 & 0.207 & 0.46 & 1.18 \\
\hline 3: Stable angina & 1.99 & 0.002 & 1.27 & 3.11 \\
\hline 4: Unstable angina & 3.70 & $<0.001$ & 2.37 & 5.77 \\
\hline 5: Non-STEMI & 7.31 & $<0.001$ & 4.72 & 11.33 \\
\hline 6: STEMI & 27.98 & $<0.001$ & 17.41 & 44.97 \\
\hline
\end{tabular}

\section{TABLE 2: Linear regression analysis for clinical variables in patients that receive $\mathrm{PCl}$.}

CAD: coronary artery disease; MI: myocardial Infarction; HF: heart failure; PCI: percutaneous coronary intervention; CABG: coronary artery bypass graft; CVD: cardiovascular disease; PAD: peripheral arterial disease; CCS: Canadian Cardiovascular Society; Non-STEMI: non-ST elevation myocardial infarction.

Comparison of CAD presentation and PCI rate demonstrated increasing odds of PCI with increased severity of CAD presentation (Figure 2). For example, odds of receiving a PCI were 0.74 in patients with no symptoms at presentation, compared with 27.9 in patients presenting with STEMI (Table 2). 


\section{Cureus}

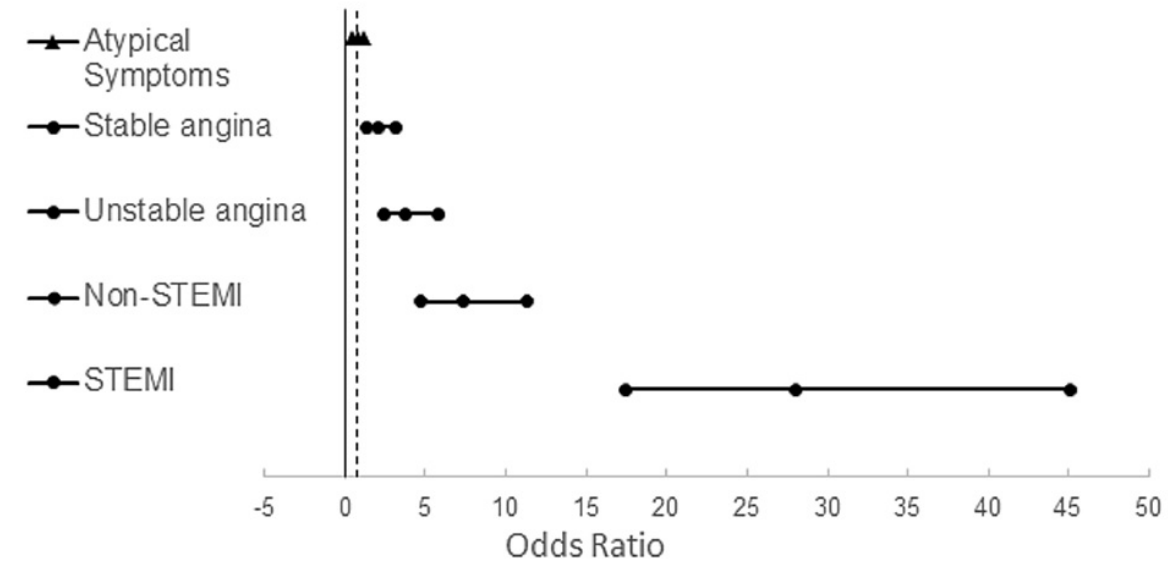

FIGURE 2: Odds ratio for $\mathrm{PCI}$ treatment among CAD presentation type.

Non-STEMI: non-ST elevation myocardial infarction; CAD: coronary artery disease; PCI: percutaneous coronary intervention.

\section{PCI treatment vs 30-day readmission and mortality}

Patients in the PCI group showed reduced odds of 30-day readmission (OR: 0.63, CI: 0.45-0.89, p = 0.009) and 30-day mortality (OR: 0.6, CI: 0.41-0.89, p =0.011) (Table 3). Interestingly, in patients who presented with NSTEMI and received PCI, 30-day mortality did not change (OR: 0.56, CI: 0.30-1.03, $\mathrm{p}=0.063$ ). 


\section{Cureus}

\begin{tabular}{|c|c|c|c|c|}
\hline \multirow{2}{*}{$\begin{array}{l}\text { 30-day readmission } \\
\text { All }\end{array}$} & \multirow{2}{*}{$\begin{array}{l}\text { Odds ratio } \\
0.63\end{array}$} & \multicolumn{2}{|c|}{$95 \% \mathrm{Cl}$} & \multirow{2}{*}{$\begin{array}{l}p \text {-value } \\
0.009\end{array}$} \\
\hline & & 0.45 & 0.89 & \\
\hline \multicolumn{5}{|l|}{ CAD presentation } \\
\hline 1: No symptoms & 0.93 & 0.11 & 7.89 & 0.947 \\
\hline 2: Atypical Symptoms & NA & & & \\
\hline 3: Stable angina & 1.61 & 0.29 & 8.81 & 0.583 \\
\hline 4: Unstable angina & 0.92 & 0.36 & 2.35 & 0.857 \\
\hline 5: Non-STEMI & 0.50 & 0.31 & 0.81 & 0.005 \\
\hline 6: STEMI & 0.67 & 0.33 & 1.37 & 0.275 \\
\hline 30-day mortality & Odds ratio & \multicolumn{2}{|c|}{$95 \% \mathrm{Cl}$} & $\mathrm{p}$-value \\
\hline All & 0.60 & 0.41 & 0.89 & 0.011 \\
\hline \multicolumn{5}{|l|}{ CAD presentation } \\
\hline 1: No symptoms & 0.35 & 0.07 & 1.68 & 0.192 \\
\hline 2: Atypical Symptoms & NA & & & \\
\hline 3: Stable angina & NA & & & \\
\hline 4: Unstable angina & 1.22 & 0.26 & 5.75 & 0.803 \\
\hline 5: Non-STEMI & 0.56 & 0.30 & 1.03 & 0.063 \\
\hline 6: STEMI & 0.60 & 0.31 & 1.16 & 0.127 \\
\hline
\end{tabular}

\section{TABLE 3: Primary outcomes for $\mathrm{PCl}$ group as reference.}

Non-STEMI: non-ST elevation myocardial infarction; CAD: coronary artery disease; PCI: percutaneous coronary intervention.

\section{PCI treatment vs cost}

PCI treatment added on average $\$ 4,731$ to the total cost of admission ( $\$ 12,753$ vs $\$ 8,022 ; p<0.001$ ) (Table 4). Notably, PCI treatment among patients that presented with stable angina ( $\$ 7450$ vs $\$ 2995 ; \mathrm{p}<0.001$ ), unstable angina ( $\$ 9,344$ vs $\$ 5361 ; \mathrm{p}<0.001)$, NSTEMI $(\$ 13,735$ vs $\$ 11,266 ; \mathrm{p}<0.001)$, and STEMI $(\$ 17,624$ vs $\$ 15,010 ; \mathrm{p}=0.025$ ) were all associated with increased cost (Figure 3). 


\section{Cureus}

\begin{tabular}{|c|c|c|c|c|c|c|}
\hline Cost & $\mathrm{PCl}$ & No $\mathrm{PCl}$ & Difference & \multicolumn{2}{|l|}{$95 \% \mathrm{Cl}$} & $p$-value \\
\hline All & $\$ 12,753$ & $\$ 8,022$ & $\$ 4,731$ & $\$ 3,699$ & $\$ 5,763$ & $<0.001$ \\
\hline \multicolumn{7}{|l|}{ CAD presentation } \\
\hline 1: No symptoms & $\$ 17,325$ & $\$ 11,072$ & $\$ 6,253$ & $-\$ 4,954$ & $\$ 17,459$ & 0.274 \\
\hline 2: Atypical Symptoms & $\$ 12,572$ & $\$ 10,475$ & $\$ 2,097$ & $-\$ 6,249$ & $\$ 10,444$ & 0.622 \\
\hline 3: Stable angina & $\$ 7,450$ & $\$ 2,995$ & $\$ 4,455$ & $\$ 3,316$ & $\$ 5,594$ & $<0.001$ \\
\hline 4: Unstable angina & $\$ 9,344$ & $\$ 5,361$ & $\$ 3,983$ & $\$ 2,378$ & $\$ 5,588$ & $<0.001$ \\
\hline 5: Non-STEMI & $\$ 13,735$ & $\$ 11,266$ & $\$ 2,468$ & $\$ 1,300$ & $\$ 3,637$ & $<0.001$ \\
\hline 6: STEMI & $\$ 17,624$ & $\$ 15,010$ & $\$ 2,613$ & $\$ 330$ & $\$ 4,897$ & 0.025 \\
\hline
\end{tabular}

TABLE 4: Generalized linear model with log link and gamma distribution analysis of $\mathrm{PCl}$ and cost.

CAD: coronary artery disease; Non-STEMI: non-ST elevation myocardial infarction; PCI: percutaneous coronary intervention.

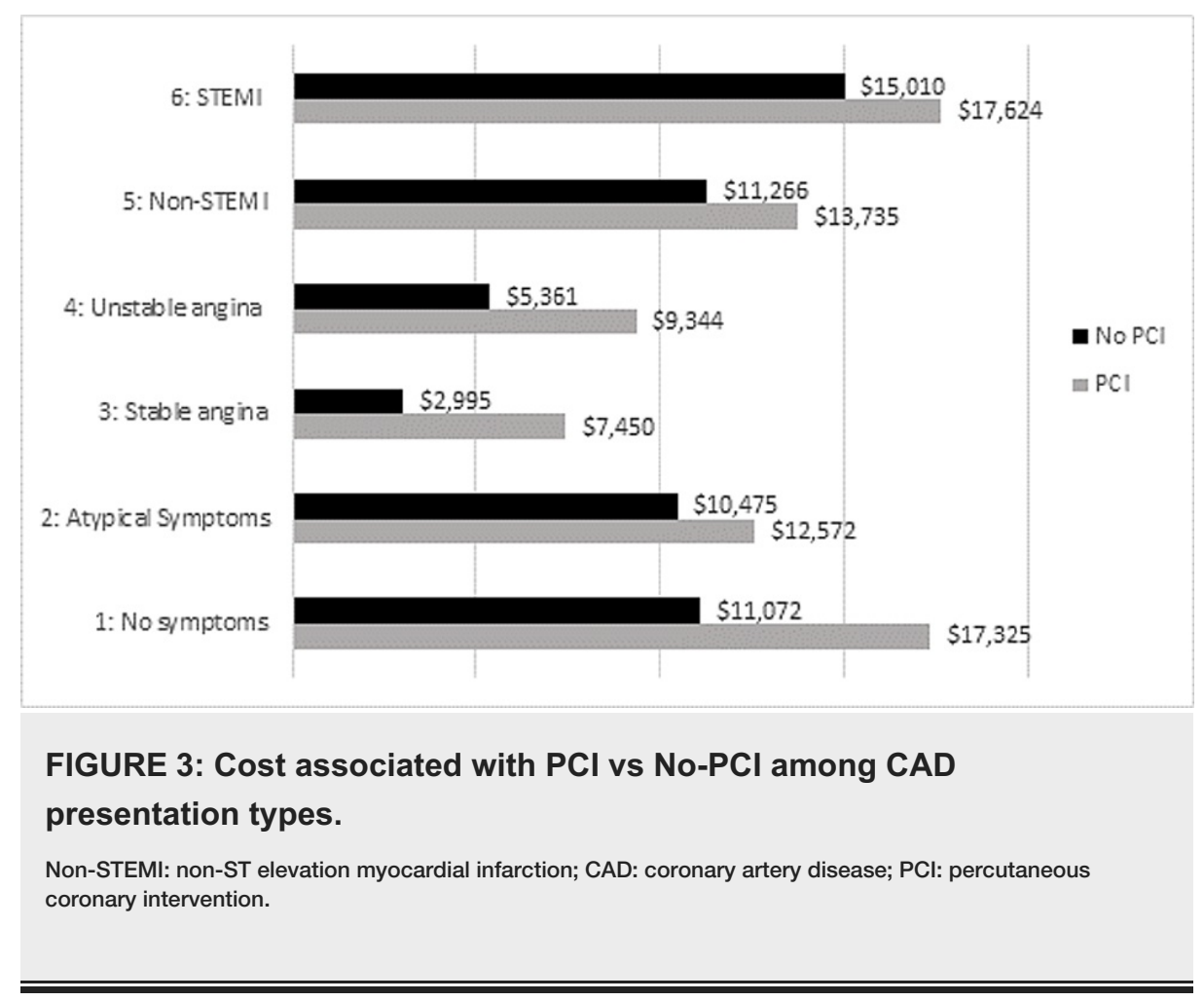

\section{Discussion}

CAD has a spectrum of presentations and mortality risk depends on which end of the spectrum the patient belongs. Regardless, all attempts are made to make sure the diagnosis of coronary artery disease is not missed, particularly with atypical presentations. This leads to a whole gamut of workup which may end up with percutaneous coronary intervention. CAD does have significant social and economic implications.

The overall cost of hospitalization depends, predominantly, whether the patient receives any kind of intervention. Many other factors further contribute to the cost including geographical location, availability of an intervention, which tercile the hospital belongs to, proficiency in complex interventions, etc. Various cost-effective analyses have been done comparing medical management and interventions. A systemic review done by Gholami et al. showed that percutaneous coronary interventions had good results in terms of quality-of-life measures and intermediate initial costs, however, required a higher need for further revascularizations [9]. On the other hand, medical therapy was associated with lower initial costs with lower quality of life measures. Caruba et al. included fifteen randomized control trials and did a network metanalysis and concluded that significant savings in the healthcare expenditure can be achieved by using 
medical therapy in stable angina patients [10].

So far there has been no study discussing the cost of hospitalization with varied presentations of CAD. Based on our analysis, we had $22.9 \%$ of the population with no or atypical symptoms who underwent a coronary angiogram, and only $3.5 \%$ received an intervention. The odds for intervention increased consistently with the rest of the presentations, stable angina through STEMI. This was reflected with respect to the cost in our economic analysis. There was no significant difference in the cost for the patients without symptoms or with atypical symptoms whether they received the intervention or not. However, with typical symptoms, there was a definite increase in the cost of the group receiving an intervention. Part of the reason for the increase in cost in the intervention group includes the duration of the stay in the hospital, which is increased as those patients required monitoring post-intervention.

\section{Limitations}

Our study is a retrospective analysis with its inherent limitations. Although the percentage of PCI goes up with the more intense presentation of $\mathrm{CAD}$, we had about $1.8 \%$ patients in the "No symptoms" group who received PCI; these are likely the patients with occult $\mathrm{CAD}$, presenting for diagnostic coronary angiogram, however because of lack of complete data on the indication, we cannot make this assumption with certainty. In addition, the difference in cost of care was highest for patients with no symptoms (\$6253), when they received a PCI; we have limited data to explain the reason for this difference as well.

30-day readmission was significantly high in the NSTEMI group, we do not have any explanation for this finding. In addition, we did not have enough data points for readmission in patients with atypical symptoms.

\section{Conclusions}

The primary outcome of mortality and 30-day readmission rates were better in the PCI group compared with the No-PCI group. The addition of PCI to coronary angiogram was associated with an increased cost of admission. Notably, PCI treatment among patients that presented with stable angina, unstable angina, NSTEMI, and STEMI was associated with significantly higher cost.

\section{Additional Information}

\section{Disclosures}

Human subjects: Consent was obtained or waived by all participants in this study. Research Institution: University of Illinois College of Medicine at Peoria, Peoria, IL issued approval 1342855. DATE: November 12, 2020 TO: Mansoor Ahmad, MD FROM: University of Illinois College of Medicine Peoria IRB 1 STUDY TITLE: [1342855-7] Clinical Predictors and Outcomes of Percutaneous Coronary Intervention (PCI): A Single Center Experience IRB REFERENCE \#: SUBMISSION TYPE: Continuing Review/Progress Report ACTION: APPROVED APPROVAL DATE: November 12, 2020 EXPIRATION DATE: November 11, 2021 REVIEW TYPE: Expedited Review. Animal subjects: All authors have confirmed that this study did not involve animal subjects or tissue. Conflicts of interest: In compliance with the ICMJE uniform disclosure form, all authors declare the following: Payment/services info: All authors have declared that no financial support was received from any organization for the submitted work. Financial relationships: All authors have declared that they have no financial relationships at present or within the previous three years with any organizations that might have an interest in the submitted work. Other relationships: All authors have declared that there are no other relationships or activities that could appear to have influenced the submitted work.

\section{References}

1. Roger VL, Go AS, Lloyd-Jones DM, et al.: Heart disease and stroke statistics--2012 update: a report from the American Heart Association. Circulation. 2012, 125:e2-e220. 10.1161/CIR.0b013e31823ac046

2. Chan PS, Patel MR, Klein LW, et al.: Appropriateness of percutaneous coronary intervention. JAMA. 2011, 306:53-61. 10.1001/jama.2011.916

3. Kwok CS, Rao SV, Potts JE, et al.: Burden of 30-day readmissions after percutaneous coronary intervention in 833,344 patients in the United States: predictors, causes, and cost: insights from the nationwide readmission database. JACC Cardiovasc Interv. 2018, 11:665-74. 10.1016/j.jcin.2018.01.248

4. Sculpher MJ, Petticrew M, Kelland JL, Elliott RA, Holdright DR, Buxton MJ: Resource allocation for chronic stable angina: a systematic review of effectiveness, costs and cost-effectiveness of alternative interventions. Health Technol Assess. 1998, 2:i-iv, 1-176.

5. Weintraub WS, Boden WE, Zhang Z, et al.: Cost-effectiveness of percutaneous coronary intervention in optimally treated stable coronary patients. Circ Cardiovasc Qual Outcomes. 2008, 1:12-20. 10.1161/CIRCOUTCOMES.108.798462

6. Zhang Z, Kolm P, Boden WE, et al.: The cost-effectiveness of percutaneous coronary intervention as a function of angina severity in patients with stable angina. Circ Cardiovasc Qual Outcomes. 2011, 4:172-82. 10.1161/CIRCOUTCOMES.110.940502

7. Mahoney EM, Jurkovitz CT, Chu H, et al.: Cost and cost-effectiveness of an early invasive vs conservative strategy for the treatment of unstable angina and non-ST-segment elevation myocardial infarction. JAMA. 


\section{Cureus}

2002, 288:1851-8. 10.1001/jama.288.15.1851

8. Jang SJ, Yeo I, Feldman DN, et al.: Associations between hospital length of stay, 30-day readmission, and costs in ST-segment-elevation myocardial infarction after primary percutaneous coronary intervention: a nationwide readmissions database analysis. J Am Heart Assoc. 2020, 9:e015503. 10.1161/JAHA.119.015503

9. Gholami SS, Azar FE, Rezapour A, Tajdini M: Cost-effectiveness of coronary artery bypass graft and percutaneous coronary intervention compared to medical therapy in patients with coronary artery disease: a systematic review. Heart Fail Rev. 2019, 24:967-75. 10.1007/s10741-019-09811-3

10. Caruba T, Katsahian S, Schramm C, et al.: Treatment for stable coronary artery disease: a network metaanalysis of cost-effectiveness studies. PLoS One. 2014, 9:e98371. 10.1371/journal.pone.0098371 